\title{
Effects of Jet Density and Exit Velocity Distribution on the Relationship between Preferred Frequency and Jet Diffusion*
}

\author{
Yuki KAWAI $^{* *}$ and Motoaki KIMURA ${ }^{* *}$ \\ ${ }^{* *}$ Nihon University, College of Science \& Technology, Department of Mechanical Engineering, \\ 1-8-14, Kanda-Surugadai, Chiyoda-ku, Tokyo 101-8308, Japan \\ E-mail: kimura@mech.cst.nihon-u.ac.jp
}

\begin{abstract}
This report aims to clarify the relationship between the preferred frequency and jet diffusion. The disturbance frequency used to control mixing, based on the preferred frequency of a flow in the initial area of the jet column mode, is often selected to enhance the diffusion of the jet flow. In the diffusive mixing enhancement of gaseous fuel and air, the properties of the jet flow and the surrounding gas differ. Thus, for the jet flow, air, $\mathrm{CO}_{2}$, and $\mathrm{He}$ were used. Three types of nozzle, convergent, orifice and pipe were used. First, the laser light sheet technique was used to visualize the cross section of the jet flow. The distance from the nozzle to the position at which the vortex rings form increases with the density ratio. The fluctuation velocity of the jet flow was measured with a hot-wire anemometer and PIV to investigate the preferred frequency and determine the Strouhal number. The Strouhal number was found not to depend on the Reynolds number and remain at an almost constant value. These findings elucidate the effects of the jet density and exit velocity distribution on the relationship between the preferred frequency and jet diffusion.
\end{abstract}

Key words: Jet, Nozzle, Diffusion, Column Mode, Density

\section{Introduction}

Many industrial fields use standard flow jets ${ }^{(1)}$. Diffusion combustion, which occurs in a combustor, is enhanced by the mixing of fuel and air with a lifted flame. Studies on the stabilization of lifted flames have progressed because of the ability to suppress NOx ${ }^{(2,3)}$. In addition, small-scale distributed generation systems are now expected to play a major role in establishing energy supply reliability as well as resolving environmental issues. Examples of such distributed generation systems include micro gas turbines that operate in the $20-200 \mathrm{~kW}$ range. In small combustors with large load fluctuation, such as those in micro gas turbines, the mixing between the fuel and discharged air is likely to deteriorate, due to a low Reynolds number; the poor mixing results from a low Reynolds number. Many efforts have been made to improve the mixing in the case of a low Reynolds number. In previous work, a coaxial confined jet with miniature flap actuators was employed ${ }^{(4-8)}$. Studies on jet diffusion control using nozzle exit shape ${ }^{(9-12)}$, coaxial film jets, and acoustic vibration ${ }^{(13)}$ have also been conducted. In many cases, for mixing enhancement, the standard preferred frequency ${ }^{(14)}$ of the jet column mode that occurs around the nozzle exit has been used to achieve the disturbance frequency. The coherent structure based on the preferred frequency around the potential core region has been observed through visualization techniques ${ }^{(15-17)}$. There are four stages in the process of the occurrence and

Received 29 Aug., 2013 (No. T2-10-0626) Japanese Original : Trans. Jpn. Soc. Mech. Eng., Vol.77, No.775, B (2011), pp.507-516 (Received 10 Aug., 2010) [DOI: 10.1299/jst.8.337]

Copyright $\odot 2013$ by JSME 
collapse of a vortex ring. In the first, a free shear layer appears due to discontinuities in the velocity between the jet and the surroundings. Next, the vortex rings roll up with Kelvin-Helmholtz (K-H) instability in the free shear layer. After that the vortex rings combine with pairing, and stream-wise vortices appear due to instability in the circumferences of the vortex rings. Finally the vortex rings collapse due to chaos ${ }^{(1,18,19)}$. Because the diffusion characteristics in the potential core region are dependent on the column mode, experiments in which jet diffusion is controlled based on the preferred frequency.

In the case of gaseous fuel and air, the density of a jet generally differs to that of its surroundings. However, very few attempts have been made to achieve variable density jet flows, such as those in the concentration and velocity measuring method work by Muramatsu and Era ${ }^{(20)}$, and the vortex structure motion in a buoyant jet with thermal jets work by Sekishita and Makita ${ }^{(21)}$. Furthermore, there have been no investigations into the relationship between a variable density jet and the Strouhal number. Hence, we have conducted such a study in this work. It is assumed that the gaseous fuel discharges, i.e., air, carbon dioxide $\left(\mathrm{CO}_{2}\right)$ and helium $(\mathrm{He})$ issue to the atmosphere. Velocity fluctuation in the potential core is measured with a hot-wire anemometer. The preferred frequency is analyzed from the data by FFT in the oscilloscope. The dependence of the Strouhal number, which is obtained from the preferred frequency, on the Reynolds number, jet density, and velocity distribution at the nozzle exit is examined, and a Strouhal number that is based on the jet diffusion control is considered. For the case of the gas being heavier than air, carbon dioxide $\left(\mathrm{CO}_{2}, \mathrm{M}=44.010\right)$ is used to model propane $\left(\mathrm{C}_{3} \mathrm{H}_{8}, \mathrm{M}=44.096\right)$, and for the case of lighter than air, helium (He, $\mathrm{M}=4.003)$ is used to model hydrogen $\left(\mathrm{H}_{2}, \mathrm{M}=2.016\right)$. Noncombustible gases are used for the experiment, because we focus on the jet diffusion just before the combustion reaction. The change in the Strouhal number, a visualization using a laser light method and the velocity distribution obtained through PIV analysis are all considered to clarify variable density jet diffusion.

\section{Experimental Apparatus}

The experimental setup is shown in Fig. 1. As shown in Fig. 2, five different nozzles with three different nozzle shapes were used to yield the velocity distributions at the nozzle exit: three convergent round nozzles, 6,8 and $10 \mathrm{~mm}$ in diameter, an orifice nozzle $8 \mathrm{~mm}$ in diameter, and a straight $1 \mathrm{~m}$ long pipe nozzle with an inner diameter of $8 \mathrm{~mm}$. The coordinate system comprises $x$ and $r$, which represent the stream-wise direction and radial direction, respectively. The gas characteristics are shown in Table 1. The gas density ratios to air are $\rho_{\text {air }} / \rho_{\text {air }}=1, \rho_{\mathrm{CO} 2} / \rho_{\text {air }}=1.53$ and $\rho_{\mathrm{He}} / \rho_{\text {Air }}=0.138^{(22)}$. Gas cylinders and an air compressor supplied $\mathrm{He}, \mathrm{CO}_{2}$, and air. The pure gas flow rate was measured by digital mass flow meters (Yamatake, CMQ0050 for $\mathrm{CO}_{2}$ and air, and CMQ0200 for He). The issuing Reynolds number range was from $R e=1 \times 10^{3}$ to $10 \times 10^{4}$ at intervals of 1000 . A condensation method was used to saturate the jet with oil particles $1 \mu \mathrm{m}$ in diameter (Shell, ONDINA Oil \#15) to allow visualization of the flow. A Nd:YAG continuous laser (Omicron, FKLA-5000e, $\lambda=532 \mathrm{~nm}, 5.5 \mathrm{~W}$ ) and high speed camera (Photron, FASTCAM SA1.1) were employed to capture the diffusion image of the center of the jet axis. The images were observed to understand the jet diffusion process, and analyzed by PIV (Ditect, DIPP-FLOW Ver.2.00e). The flow velocity was measured in order to examine the preferred frequency. Because the potential core length depends on the gas used, the velocity measurement positions were $x / d=2,3,4$ for air and $\mathrm{CO}_{2}$, and $x / d=1,1.5,2$ for He. These measurements were made using an I-type hot-wire (KANOMAX, Model 0251R-T5, tungsten wire diameter: $5 \mu \mathrm{m}$, length: $1 \mathrm{~mm}$ ) and anemometer system (KANOMAX, Model $1008,1010,1013,1075)$. The velocity fluctuation was observed with an oscilloscope and analyzed by FFT to obtain the frequency peak: $f_{o}$ (preferred frequency) of the measured 


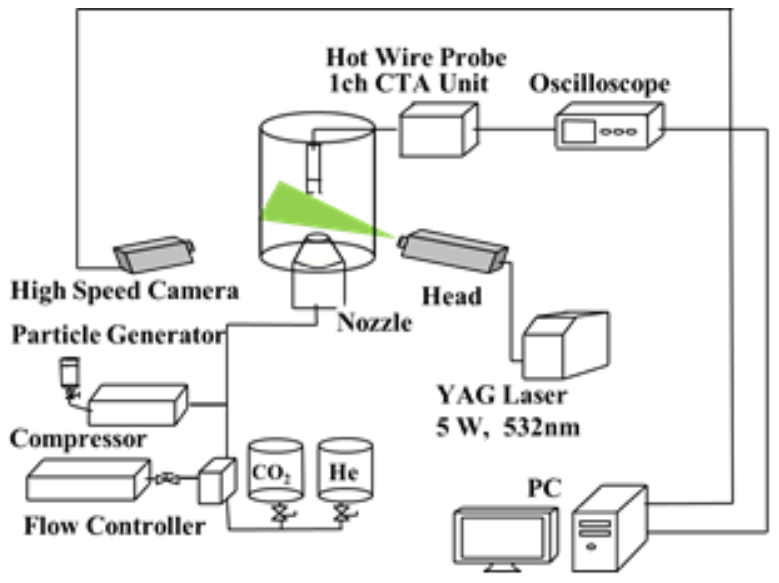

Fig. 1 Experimental apparatus.

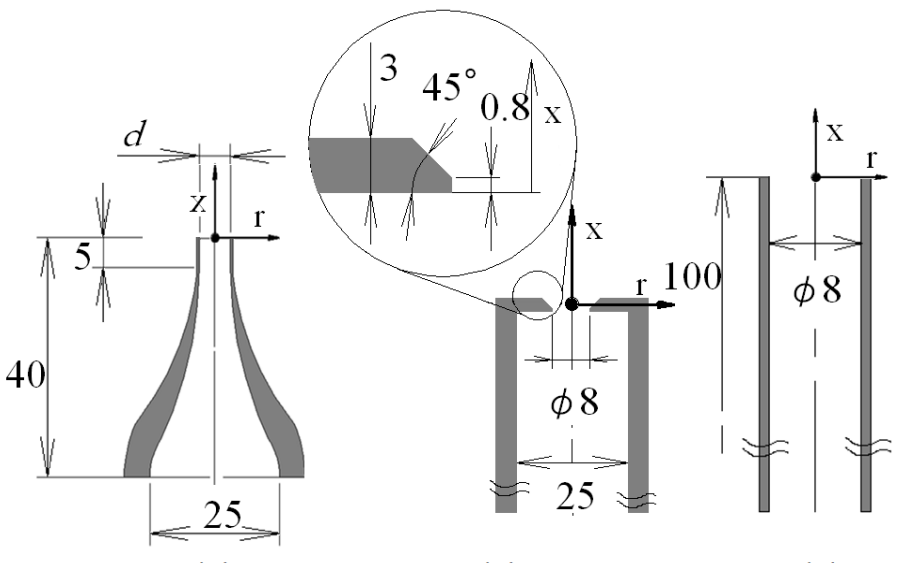

(a)

(b)

(c)

Fig. 2 Nozzle shapes [mm] (a) Convergent nozzle, $d=6,8,10 \mathrm{~mm}$, (b) Orifice nozzle, (c) Pipe nozzle.

Table 1 Gas characteristics $(298 \mathrm{~K}, 0.1 \mathrm{MPa})^{(22)}$

\begin{tabular}{|l|c|c|c|}
\hline & $\begin{array}{l}\text { Carbon } \\
\text { dioxide }\end{array}$ & Air & Helium \\
\hline Density $\left[\mathrm{kg} / \mathrm{m}^{3}\right]$ & 1.811 & 1.184 & 0.163 \\
\hline Viscosity $[\mu \mathrm{Pa} \mathrm{s}]$ & 14.9 & 18.4 & 19.80 \\
\hline $\begin{array}{l}\text { Kinematic } \\
\text { Viscosity }\left[\mathrm{mm}^{2} / \mathrm{s}\right]\end{array}$ & 8.23 & 15.5 & 121 \\
\hline $\begin{array}{l}\text { Heat Conductivity } \\
[\mathrm{mW} / \mathrm{m} \cdot \mathrm{K})]\end{array}$ & 16.5 & 25.9 & 149.3 \\
$\begin{array}{l}\text { Density ratio } \\
\rho / \rho \text { Air }[-]\end{array}$ & 1.530 & 1.000 & 0.138 \\
\hline
\end{tabular}

power spectra. The Strouhal number $\left(S t=f_{o} d / U_{m}\right)$ is dependent on the preferred frequency, $f_{o}$, issuing velocity, $U_{m}$, and nozzle exit diameter, $d$. The preferred frequency was averaged over five measurements. In the case of a variable density jet diffusion, measurements using the hot-wire anemometer were difficult due to the varying thermal conductivity. The hot-wire was calibrated in pure gas $(100 \%)$ in a pure gas container to $0 \mathrm{~m} / \mathrm{s}$, and in the potential core region $(x / d=0.5)$ for any velocity. The nozzle directions were either vertically upward or downward, in orders to investigate the influence of buoyancy effects. 


\section{Results and Discussion}

\subsection{Velocity Distribution at Nozzle Exit}

Figure 3 shows the mean velocity profiles, $U / U_{m}$, and turbulent intensity profiles, $u^{\prime} / U_{m}$, for three nozzle types around the nozzle exit at $x / d=0.5$, in the case of $R e=3 \times 10^{3} . U$ is the mean velocity, $u^{\prime}$ is the root mean square of the fluctuation velocity, $U_{m}$ is the mean velocity at the nozzle exit of a convergent round nozzle used to compare the velocity profiles of the other three nozzle types. The mean velocity distribution of the convergent round nozzle has a unique top hat shape. In the case of the orifice nozzle, the mean velocity increases around the potential core center due to the contraction effect, and there is a small peak near the nozzle edge ${ }^{(10,11)}$. The pipe nozzle, however, has a far greater length $(1 \mathrm{~m})$ than its inner diameter $(8 \mathrm{~mm})$, resulting in the mean velocity distribution becoming the developed pipe flow profile, in which the velocity is highest in the center, due to the viscous wall layer. The fluctuation velocity was most intense around the nozzle edge, and was smallest at the center of all nozzles. The peak fluctuation velocity of the orifice nozzle was about 10 times that of the convergent round nozzle.

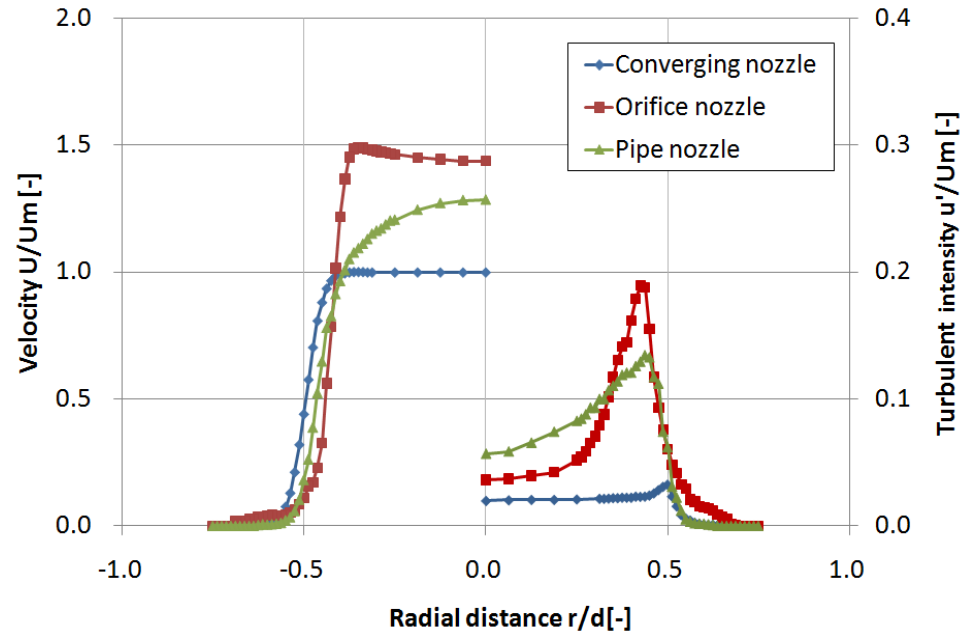

Fig. 3 Mean velocity distribution and turbulent intensity at nozzle exit (air, $d=8 \mathrm{~mm}$, $x / d=0.5, R e=3000)$.

\subsection{Visualization of Jet Diffusion of Carbon Dioxide and Air, and PIV Analysis}

Figures 4 and 5 show the visualization and PIV analyzed vector of the $\mathrm{CO}_{2}$ jet and the air jet in the case of the convergent round nozzle, $d=8 \mathrm{~mm}, R e=3 \times 10^{3}$. The three images are (a) the original visualization image, (b) the instantaneous PIV data and (c) the averaged

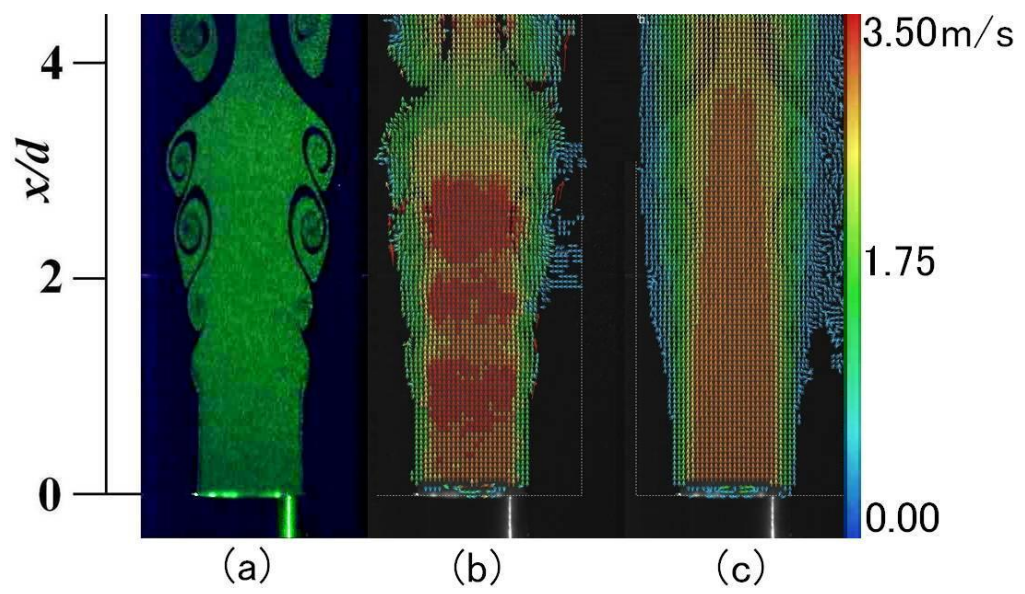

Fig. 4 Visualization of jet diffusion and velocity vector with PIV analysis $\left(\mathrm{CO}_{2}, d=8\right.$ $\mathrm{mm}, R e=3000$, Convergent nozzle, (a) Original, (b) Instantaneous PIV, (c) Average PIV). 


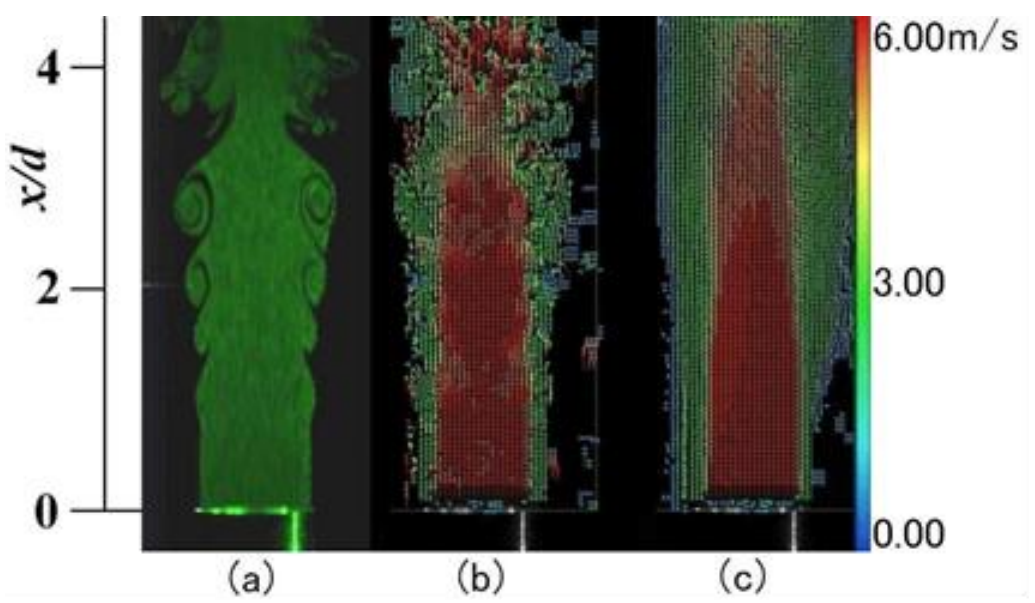

Fig. 5 Visualization of jet diffusion and velocity vector with PIV analysis (Air, $d=8$ mm, $R e=3000$, Convergent nozzle, (a) Original, (b) Instantaneous PIV, (c) Average PIV).

PIV data. The preferred frequency is the frequency of the fluctuation velocity that results from the passing of vortex rings and their pairing around the potential core region. The vortex rings roll up from the generation of shear instability at the interface dividing the jet flow and the ambient air. As shown in Figs. 4(b) and 5(b), the central velocity in the potential core region varies due to the passing of vortex rings. In the case of the He jet, the PIV system could not provide analysis because the jet flow velocity was outside the measurable range.

\subsection{Relationships between Strouhal Number and Jet Density and Reynolds Number}

The relationship between the Reynolds number and the issuing Strouhal number, as well as the relationship between the jet gas density and the Strouhal number were examined using the convergent circular nozzle. Figure 6 shows the visualization of the different gases

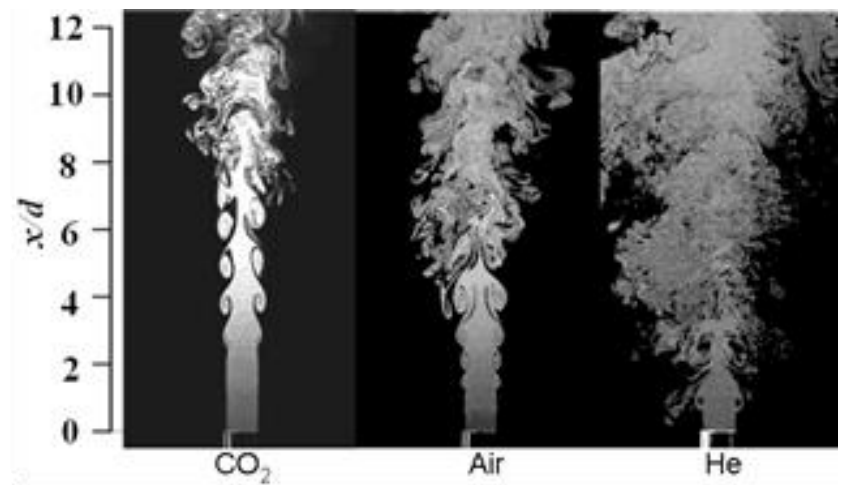

Fig. 6 Visualization of flow (Convergent nozzle, $d=8 \mathrm{~mm}, \operatorname{Re}=3000$ ).

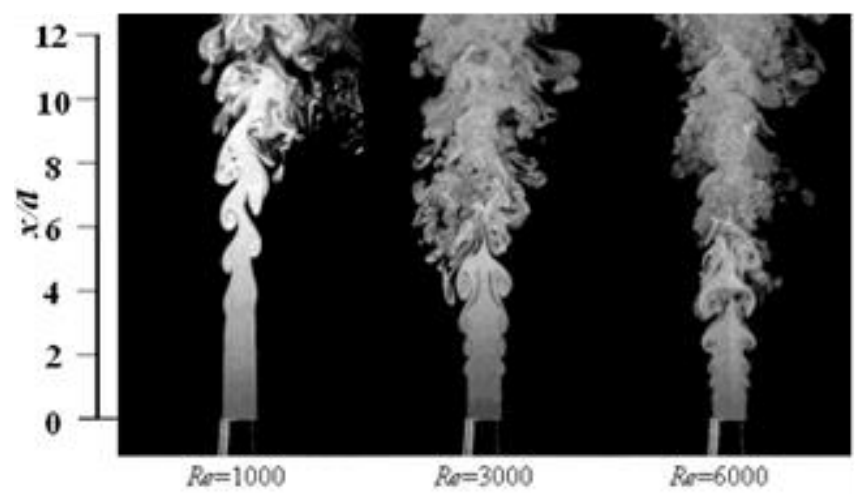

Fig. 7 Visualization of flow (Convergent nozzle, Air, $d=8 \mathrm{~mm}$ ). 
ejected from the convergent nozzle $(R e=3000)$. The characteristics of the diffusion process in the vicinity of the nozzle were observed; furthermore, it was confirmed that the distance from the nozzle at which the vortex rings collapse varies depending on the type of gas. Irregularities appear in the free boundary layer due to the $\mathrm{K}-\mathrm{H}$ instability, and the vortex rings grow unevenly. Vortex ring represents the face three-dimensional while combined, it is possible to observe characteristics of the diffusion process through visualization of their collapse $^{(1,19)}$. The distance from the nozzle outlet at which the vortex rings form increases with the density ratio $\left(\rho / \rho_{\text {air }}\right)$ of the jet and the surrounding gas. Figure 7 is a visualization of the air ejected from the convergent circular nozzle with different Reynolds numbers $(R e=$ $1000,3000,6000)$. The figure shows that the position at which the vortex rings occur approaches the nozzle as the Reynolds number is increased.

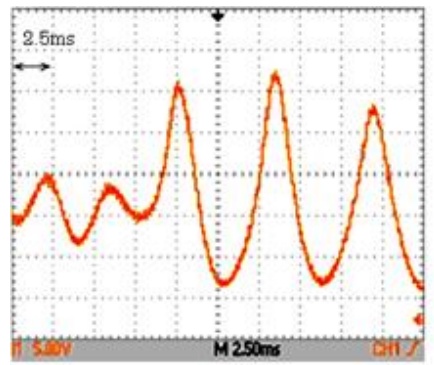

(a)

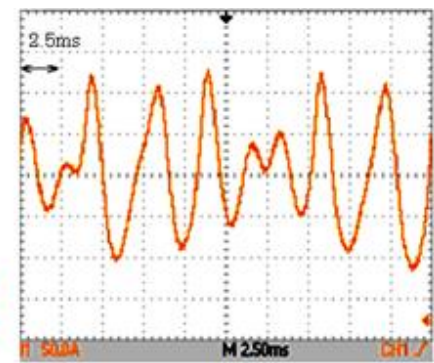

(b)

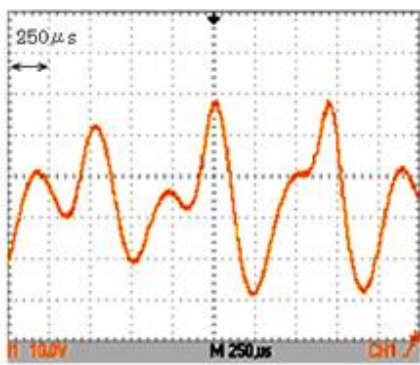

(c)

Fig. 8 Sample of the velocity fluctuations in the potential core region $(\operatorname{Re}=3000, d=8$ mm, Convergent nozzle, (a) $\mathrm{CO}_{2}: x / d=4$, (b) Air: $x / d=4$, (c) He: $x / d=1.5$ ).

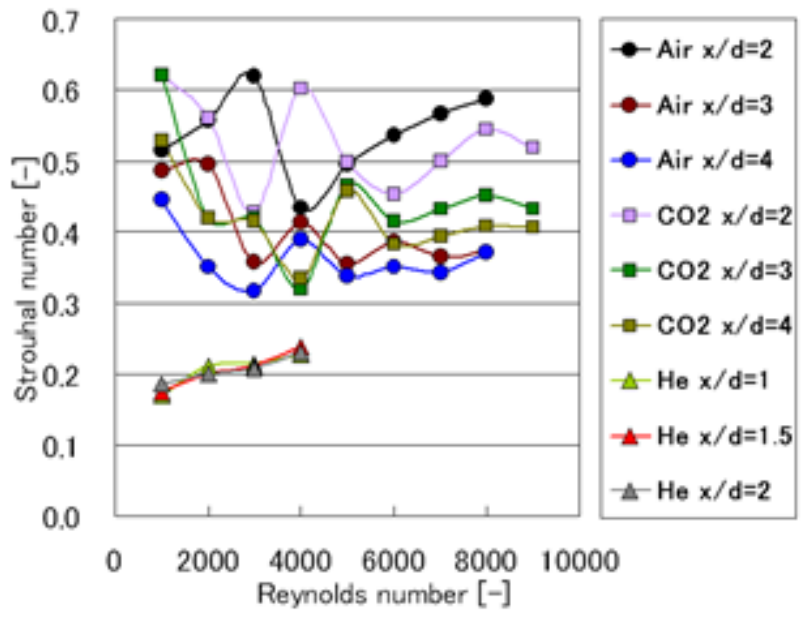

Fig. 9 Strouhal number at various measurement locations $(\mathrm{d}=8 \mathrm{~mm})$.

As was confirmed in Section 3.2, due to the vortex rings, the jet velocity in the potential core region fluctuates. Figure 8 shows the output of a hot-wire anemometer inserted into the potential core region. The resulting waveform resembles a sine wave whose frequency and maximum amplitude also vary with time. The peak of the spectrum of the hot-wire output shows a broadband distribution except $\mathrm{He}$, there is a certain width in frequency to be obtained. Figure 9 shows the Strouhal number at different measurement positions for the three gases. The Strouhal number at the nozzle near the start of the K-H instability $\left(\mathrm{CO}_{2}: x / d\right.$ $=2$, air: $x / d=2$, He: $x / d=1)$ is larger than at the formation of the vortex rings $\left(\mathrm{CO}_{2}: x / d=\right.$ 4, air: $x / d=4$, He: $x / d=2$ ). At the position where the vortex rings form, the Strouhal numbers $(S t)$ were always found within a certain range regardless of the Reynolds number $\left(\mathrm{CO}_{2}: S t=0.38-0.45\right.$, Air: $S t=0.32-0.41$, He: $\left.S t=0.19-0.23\right)$. It was considered that velocity cycle is changed by a passing interval of vortex ring are because stable. Figure 10 shows the Strouhal numbers for different outlet diameters of the convergent circular nozzle 


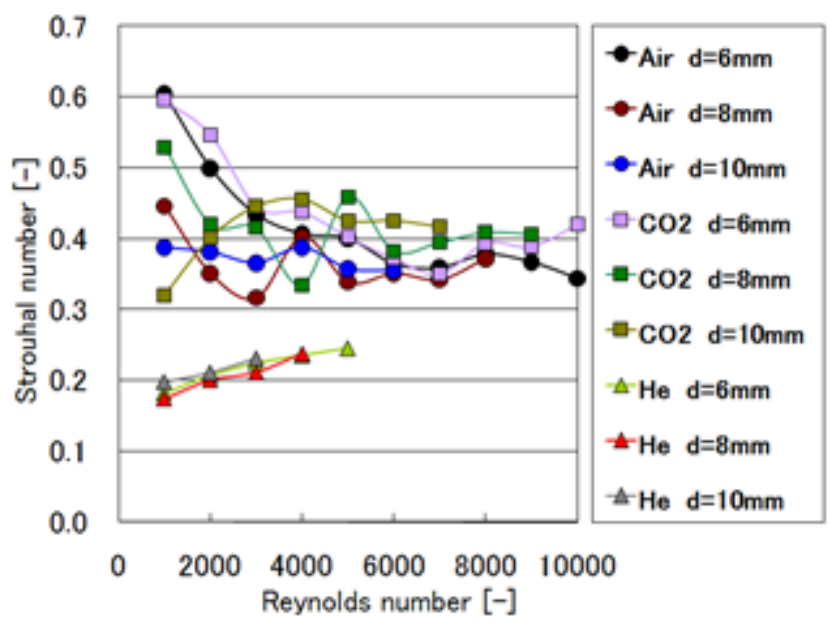

Fig. 10 Strouhal number with various nozzle diameters $\left(\mathrm{CO}_{2}: x / d=4\right.$, Air: $x / d=4$, He: $x / d=1.5)$.

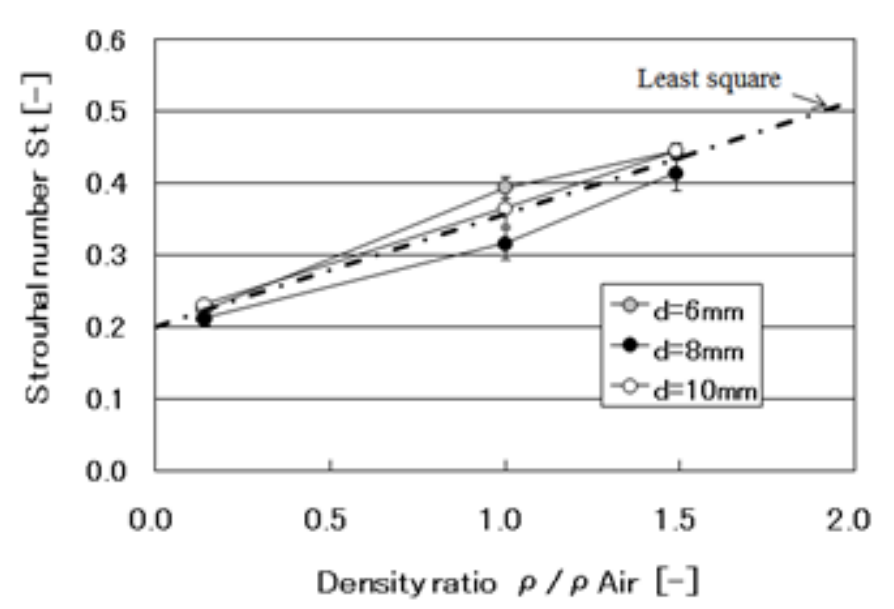

Fig. 11 Relation between Strouhal number and density ratio $(\operatorname{Re}=3000)$.

$\left(\mathrm{CO}_{2}: x / d=4\right.$, air: $x / d=4$, He: $\left.x / d=1.5\right)$. The Strouhal number remained almost constant for the different diameters $\left(\mathrm{CO}_{2}: S t=0.39-0.41\right.$, air: $S t=0.32-0.40$, He: $\left.S t=0.19-0.24\right)$. Figure 11 shows the relationship between the Strouhal number and the density ratio $\left(\rho / \rho_{\text {air }}\right)$. The standard deviation of the experimental values is indicated with error bars and the linear lines of best fit were obtained using the least squares method. The Strouhal number increases with increasing density ratio.

\subsection{Relationship between the Strouhal number and the exit velocity distribution of different nozzle shapes}

As discussed in Section 3.1, the relationship between the exit velocity distributions of the convergent nozzle, the orifice nozzle and the pipe nozzle and the Strouhal number was investigated. Figures 12 and 13 show the visualizations for Reynolds numbers of $R e=3000$ and 4000, respectively, for the three nozzle shapes. The flow rates in the pipe and orifice nozzle were set to yield the same Reynolds number as in the convergent nozzle.

The separation of the vortex rings produced by the orifice nozzle (b) is smaller than that in the case of the convergent nozzle (a). As highlighted in Section 3.1, the velocity of the outer edges of the jet increases due to the flow contraction effect of the orifice, the velocity difference between the stationary air and the jet becomes large, and the distance between the vortex rings decreases. With $R e=3000$, the pipe nozzle (c) did not generate a vortex ring. It was considered that the wall boundary layer resulting from the wall friction of the straight tube yields a gentle velocity distribution, which does not disturb the surrounding gas, and 


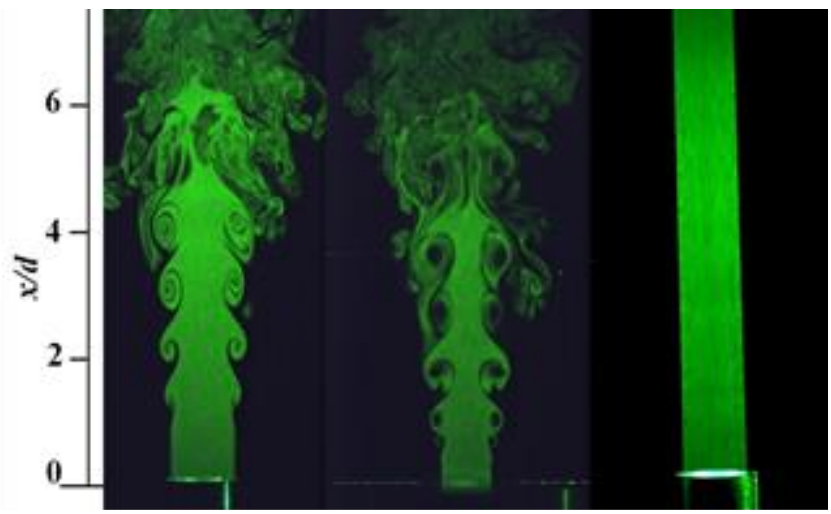

(a)

(b)

(c)

Fig. 12 Visualization of flow (Air, $R e=3000$, (a) Convergent nozzle, (b) Orifice nozzle, (c) Pipe nozzle).

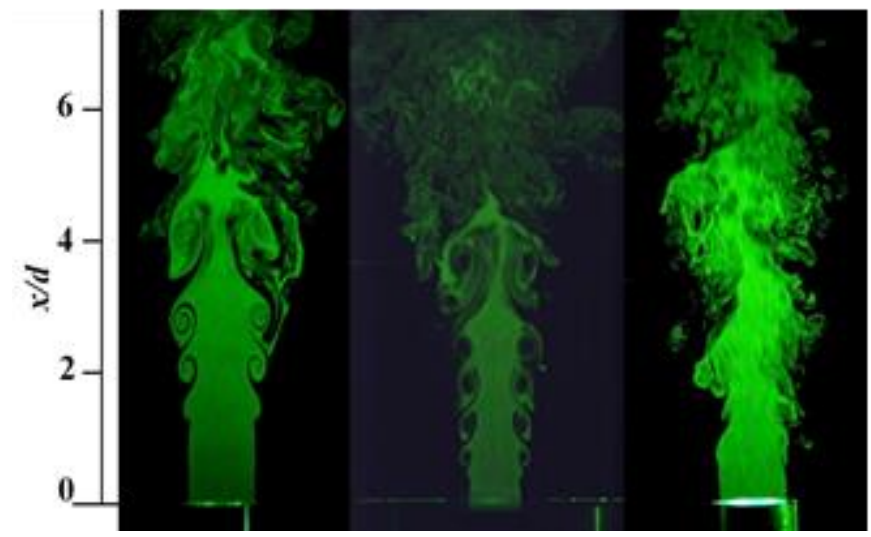

(a)

(b)

(c)

Fig. 13 Visualization of flow (Air, $R e=4000$, (a) Convergent nozzle, (b) Orifice nozzle, (c) Pipe nozzle).

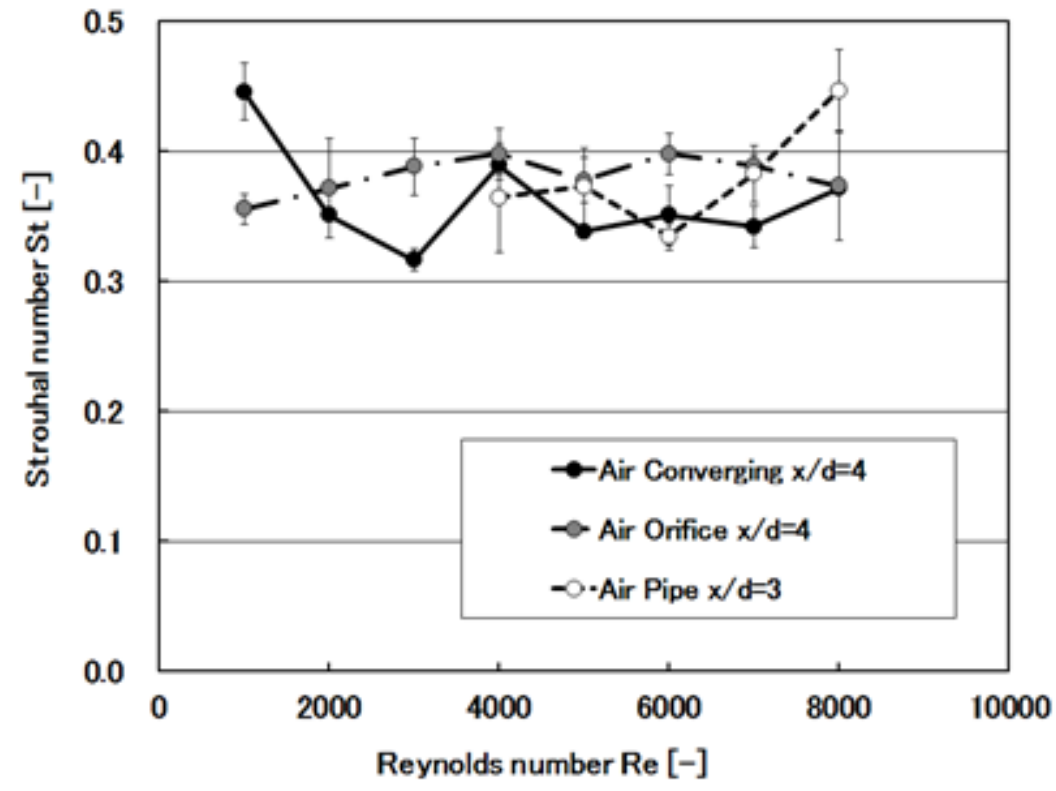

Fig. 14 Relation between Strouhal number and Reynolds number (Air).

vortex rings do not occur. The case of $R e=4000$, however, is a turbulent state.

Figure 14 shows the relationship between the Reynolds number and Strouhal number for the different nozzles using air measured with the hot-wire. Variations in the experimental measurements of the frequency are shown by the standard deviation error 
bars. Vortex rings were not generated for $R e=1000,2000,3000$ with the pipe nozzle, so no results are given. The Strouhal number was almost constant at 0.38 regardless of the Reynolds number for all nozzles. It is believed that the preferred frequency increases as the separation of subsequent vortex rings decreases as shown by the visualization of the orifice jet in Fig. 12, but Strouhal number so that acceleration also jet velocity due to the effect of the reduced flow fact is not seen by the nozzle change shape to.

\subsection{Effect of buoyancy on the Strouhal number}

Figure 15 shows the change in the Strouhal number for $\mathrm{CO}_{2}$ and $\mathrm{He}$ using the convergent round nozzle aimed vertically upwards and downwards in turn to examine the effects of buoyancy on the Strouhal number. The standard deviation is indicated by error bars. Solid lines indicate the upward jets and dashed lines indicate the downward jets. And when it is ejected vertically in either gas is within the error bars Strouhal number. Hence, it was considered that buoyancy has negligible effect on the Strouhal number, the inertial force is dominant, and therefore the effects of buoyancy do not appear in the potential core region. Figure 16 shows the central axis mean velocity distribution obtained with PIV analysis for $\mathrm{CO}_{2}$ issued upwards and downwards. In the potential core region, the ejection speed of the upwards issuing jet decreases faster that the downwards issuing jet. It is believed that this is the influence of buoyancy, but the decrease in average velocity was very small, $1.6 \%$ or less at the position of $x / d=2$, and smaller still with the downwards jet. Figure 17 shows the relationship between the preferred frequency and the jet velocity for $\mathrm{He}$ and $\mathrm{CO}_{2}$. It is shown that the preferred frequency increases in proportion to the ejection velocity.

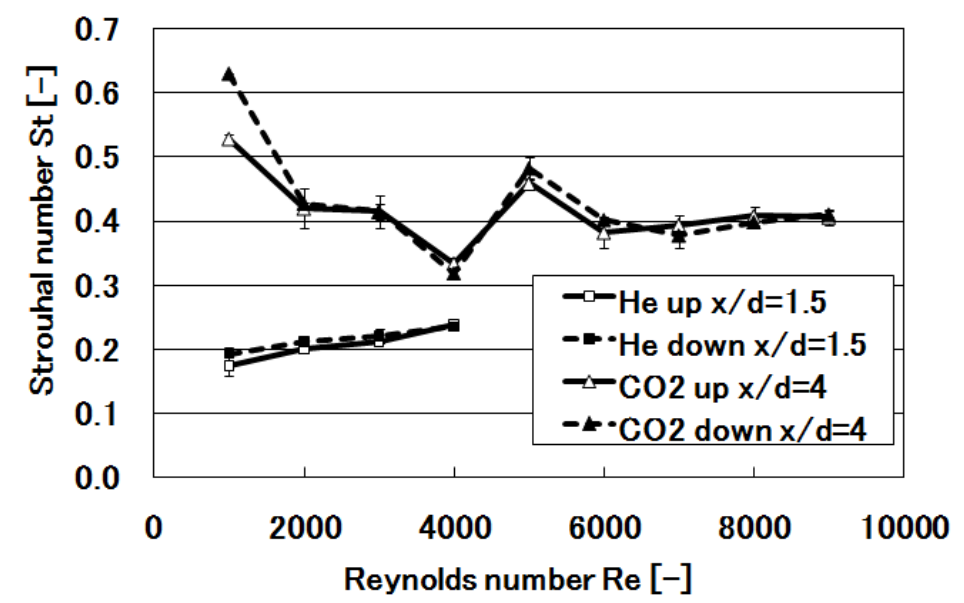

Fig. 15 Relation between Strouhal number and Reynolds number.

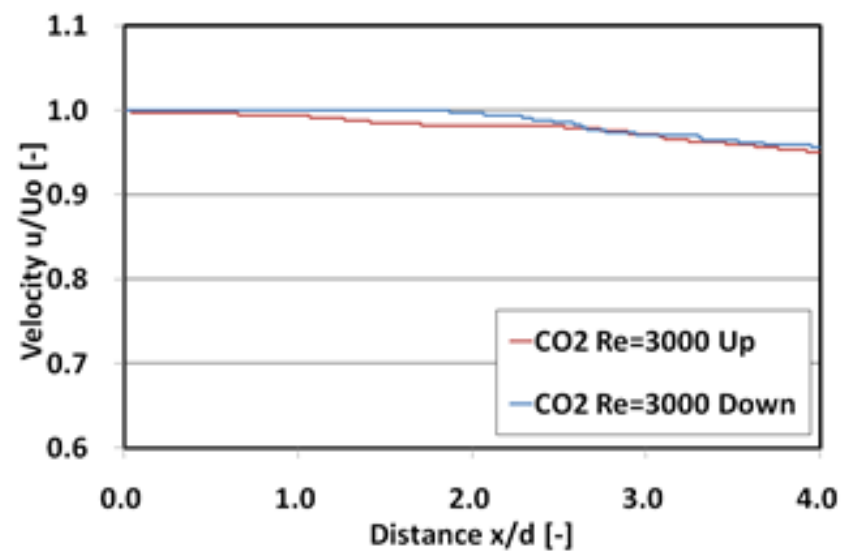

Fig. 16 Relation between velocity and distance from nozzle exit $\left(\mathrm{CO}_{2}, \mathrm{Re}=3000\right)$. 


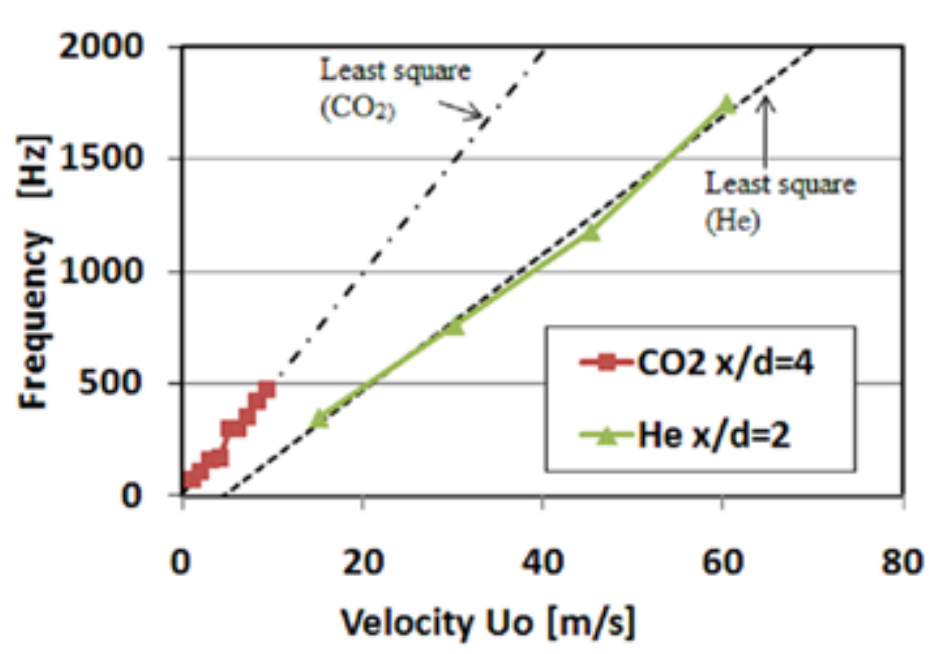

Fig. 17 Relation between frequency and issuing velocity $(d=8 \mathrm{~mm})$.

\section{Conclusions}

We examined the effects of the exit velocity distribution and jet gas density on the relationship between the preferred frequency and jet diffusion, and concluded the following:

1. The Strouhal number of $\mathrm{He}$ and $\mathrm{CO}_{2}$ jets settles within a certain range regardless of the Reynolds number, shown by measurements of the preferred frequency.

2. The Strouhal number increases almost linearly with the surrounding gas to ejection gas density ratio.

3. The Strouhal number remains almost constant regardless of the nozzle diameters used in this study.

4. The distance from the position of nozzle instability to the position of vortex ring formation increases with increasing density ratio.

5. The contraction flow action reduces the separation between subsequent vortex rings, and the formation position with the orifice nozzle is close to the nozzle opening.

6. Due to a decrease in velocity at the nozzle wall near due to the development of a wall boundary layer, the formation of vortex rings is suppressed in the pipe nozzle.

7. The Strouhal number remains constant regardless of the influence of the nozzle shape on the outlet velocity distribution.

8. The results indicate that buoyancy effects have little influence on the potential core region, because buoyancy is dominated by the inertial force.

\section{Acknowledgements}

The present study was supported by Grants-in-Aid for Scientific Research (C) (JSPS KAKENHI No. 22560176).

\section{References}

(1) Shakouchi, T., Jet Flow Engineering -Fundamentals and Application-, (2004), Morikita Publishing.

(2) Hirota, M., Hashimoto, K., Oso, H. and Masuya, G., Improvement of Laminar Lifted Flame Stability Excited by High Frequency Acoustic Oscillation, Transactions of the Japan Society of Mechanical Engineers, Series B, Vol.74,No.748(2008), pp.2697-2703.

(3) Hirota, M., Sekine, K., Hashimoto, K., Saiki, A., Takahashi, H. and Masuya, G., Measurement of Fuel Concentration Profile at Leading Edge of Lifted Flame with Acetone Laser-Induced Fluorescence, Transactions of the Japan Society of Mechanical Engineers, Series B, Vol.73,No.728(2007), pp.1107-1113. 
(4) Suzuki, H., Kasagi, N. and Suzuki, Y, Active Control of Axisymmetric Jet with an Array of Micro Electro-Magnetic Flap Actuators, Transactions of the Japan Society of Mechanical Engineers, Series B, Vol.65,No.639(1999), pp.3644-3651.

(5) Saiki, Y., Kurimoto, N., Suzuki, Y. and Kasagi, N., Temperature Measurement with a Conditional Two-line OH-PLIF Technique in an Actively Controlled Coaxial Jet Flame, Transactions of the Japan Society of Mechanical Engineers, Series B, Vol.73,No.732(2007), pp.1678-1686.

(6) Kasagi, N., Toward Smart Control of Turbulent Jet Mixing and Combustion, JSME International Journal, Series B, Vol.49, No.4(2006), pp.941-950.

(7) Kurimoto, N., Saiki, Y., Suzuki, Y. and Kasagi, N., Active Control of Premixed Flame in a Model Combustor with Arrayed Micro Actuators, Transactions of the Japan Society of Mechanical Engineers, Series B, Vol.74,No.744(2008), pp.1843-1852.

(8) Kurimoto, N., Suzuki, Y. and Kasagi, N., Active Control of Coaxial Jet Mixing with Arrayed Micro Actuators, Transactions of the Japan Society of Mechanical Engineers, Series B, Vol.70,No.694(2004), pp.1417-1424.

(9) Mori, H., Toyoda, K., Hiramoto, R. and Shirahama, Y., Interaction of Vortex Rings and Streamwise Vortices in an Axisymmetric Jet, Transactions of the Japan Society of Mechanical Engineers, Series B, Vol.70,No.697(2004), pp.2265-2271.

(10) Kito, M., Shakouchi, T., Nuntadusit, C., Tsujimoto, K. and Ando, T., Flow Control of Orifice Free Jet by Nozzle Plate Thickness, Transactions of the Japan Society of Mechanical Engineers, Series B, Vol.74,No.745(2008), pp.1935-1941.

(11) Shakouchi, T., Kito, M., Kasamoto, T., Tsujimoto, K. and Ando, T., Flow Analysis of Orifice Free Jet (Effects of Contraction Ratio), Transactions of the Japan Society of Mechanical Engineers, Series B, Vol.74,No.737(2008), pp.42-48.

(12) Shakouchi, T., Kito, M., Sato, K., Tsujimoto, K. and Ando, T., Jet Diffusion Enhancement and Control of Orifice Free Jet, Journal of the Japan Society for Aeronautical and Space Sciences, Vol.57,No.663(2009), pp.160-165.

(13) Miyagi, N., Kimura, M., Shoji, H., Fujita, H. and Hodoya, K., Study of Active Jet Control by Acoustically driven Secondary Film Flow (A change of Quantity of Entrainment), Transactions of the Japan Society of Mechanical Engineers, Series B, Vol.71,No.712(2005), pp.2870-2877.

(14) Ho, C. M. and Huerre, P., Perturbed free shear layers, Transactions of the Annual Reviews Fluid Mechanics, Vol.16(1984), pp.365-424.

(15) Van Dyke, M., An Alboume of Fluid Motion, (1982), p.70-71, The Parabolic press.

(16) Lau, J. C., Fisher, M. J. and Fuchs, H.V., The intrinsic structure of turbulent jets, Journal of Sound and Vibration, Vol.22,No.4(1972), pp.379-406.

(17) Hussain, A. K. M. F. and Zaman, B. M. Q., The preferred mode of the axisymmetric jet, Journal of Fluid Mechanics, Vol.110(1981), pp. 39-71.

(18) Toyoda, K., Vortices in Jets, Journal of Japan Society of Fluid Mechanics, Vol.24 (2005), pp.151-160.

(19) Liepmann, D. and Gharib, M., The role of streamwise vorticity in the near-field entrainment of round jets, Journal of Fluid Mechanics, Vol.245(1992), pp.643-668.

(20) Muramatsu, A. and Era, Y., Measurements of Concentration and Velocity in a Gas Mixture (A Method Utilizing a Piezoresistive Sensor and a Hot-Wire Concentration Probe), Transactions of the Japan Society of Mechanical Engineers, Series B, Vol.64,No.624(1998), pp.2632-2639.

(21) Sekihsita, N. and Makita, H., Behavior of Vortex Structure in a Round Buoyant Jet (Visualization Experiments), Proceedings of Mechanical Engineering Congress 2000 Japan of the Japan Society of Mechanical Engineers, No.05-1(2005-9), pp.329-330.

(22) The Japan Society of Mechanical Engineers ed., JSME Date Book: Thermophysical Properties of Fluids, (1982), pp.8-12, The Japan Society of Mechanical Engineers. 